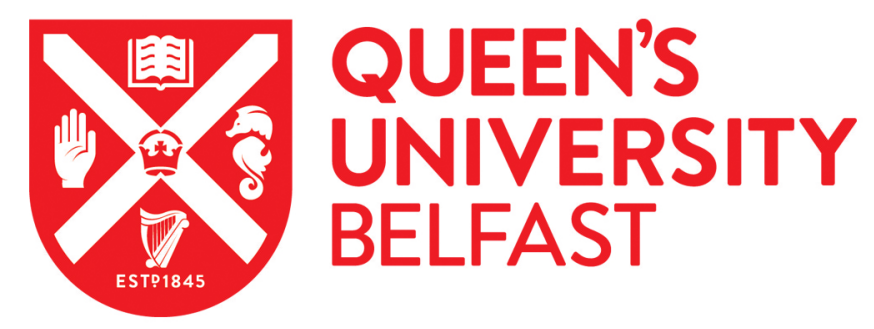

\title{
Investigation of influence of process variables on mechanical strength, size and homogeneity of pharmaceutical granules produced by fluidised hot melt granulation
}

Mangwandi, C., Zainal, N. A., JiangTao, L., Glocheux, Y., \& Albadarin, A. B. (2015). Investigation of influence of process variables on mechanical strength, size and homogeneity of pharmaceutical granules produced by fluidised hot melt granulation. Powder Technology, 272, 173-180. https://doi.org/10.1016/j.powtec.2014.11.042

Published in:

Powder Technology

Document Version:

Peer reviewed version

Queen's University Belfast - Research Portal:

Link to publication record in Queen's University Belfast Research Portal

\begin{abstract}
Publisher rights
This is the author's version of a work that was accepted for publication in Powder Technology. Changes resulting from the publishing process, such as peer review, editing, corrections, structural formatting, and other quality control mechanisms may not be reflected in this document. Changes may have been made to this work since it was submitted for publication. A definitive version was subsequently published in Powder Technology, vol 272, issue March 2015 doi: 10.1016/j.powtec.2014.11.042.
\end{abstract}

\section{General rights}

Copyright for the publications made accessible via the Queen's University Belfast Research Portal is retained by the author(s) and / or other copyright owners and it is a condition of accessing these publications that users recognise and abide by the legal requirements associated with these rights.

Take down policy

The Research Portal is Queen's institutional repository that provides access to Queen's research output. Every effort has been made to ensure that content in the Research Portal does not infringe any person's rights, or applicable UK laws. If you discover content in the Research Portal that you believe breaches copyright or violates any law, please contact openaccess@qub.ac.uk. 
4

\section{INVESTIGATION OF INFLUENCE OF PROCESS VARIABLES ON MECHANICAL STRENGTH, SIZE AND HOMOGENEITY OF PHARMACEUTICAL GRANULES PRODUCED BY FLUIDISED HOT MELT GRANULATION}

Chirangano Mangwandi ${ }^{*}$, N. A. Zainal ${ }^{1}$, Liu JiangTao ${ }^{1}$, Y. Glocheux ${ }^{1}$, Ahmad B. Albadarin ${ }^{1,2}$
${ }^{1}$ School of Chemistry and Chemical Engineering, Queen's University Belfast, Belfast BT9 5AG, Northern Ireland UK ${ }^{2}$ Synthesis \& Solid State Pharmaceuticals Center (SSPC), Department of Chemical and Environmental Science, University of Limerick, Ireland.

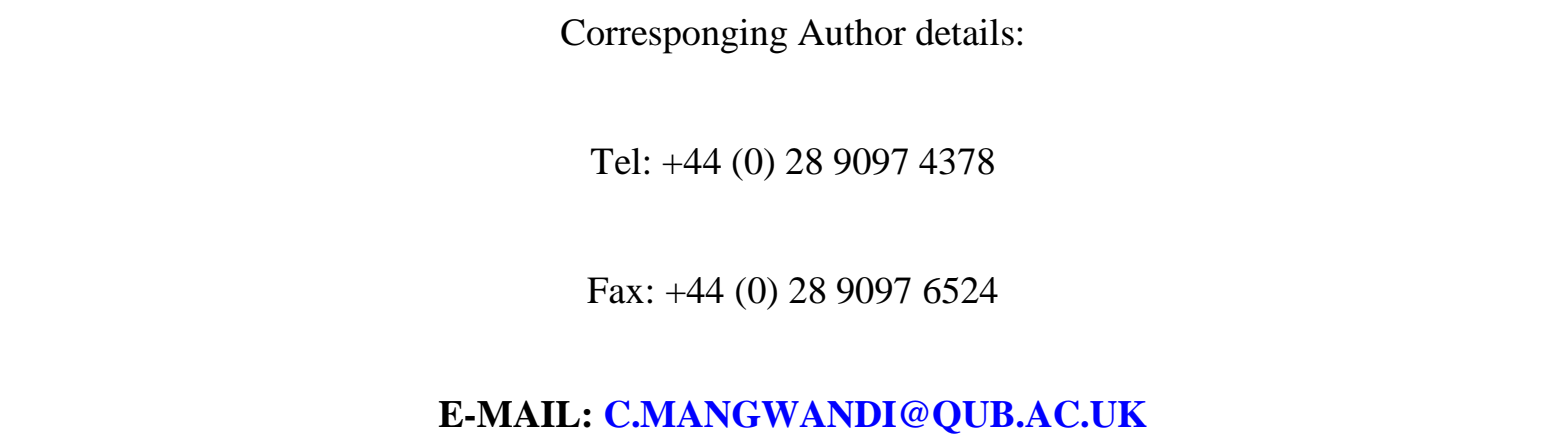

20 Keywords: Active pharmaceutical ingredient; homogeneity; granule strength; granule size;

21 Fluidised hot melt granulation (FHMG); methylene blue 


\title{
INVESTIGATION OF INFLUENCE OF PROCESS VARIABLES ON MECHANICAL STRENGTH, SIZE AND HOMOGENEITY OF PHARMACEUTICAL GRANULES PRODUCED BY FLUIDISED HOT MELT GRANULATION
}

\author{
C. Mangwandi ${ }^{*}$, N. A. Zainal ${ }^{1}$, Liu JiangTao ${ }^{1}$, Y. Glocheux ${ }^{1}$, A.B. Albadarin ${ }^{1,2}$ \\ ${ }^{1}$ School of Chemistry and Chemical Engineering, Queen's University Belfast, \\ Belfast BT9 5AG, Northern Ireland UK \\ ${ }^{2}$ Materials Surface Science Institute, Department of Chemical and Environmental Sciences, \\ University of Limerick, Ireland.
}

\section{ABSTRACT}

The overall aim of the project was to study the influence of process variables on the distribution of a model active pharmaceutical ingredient (API) during fluidised melt granulation of pharmaceutical granules with a view of optimising product characteristics. Granules were produced using common pharmaceutical excipients; lactose monohydrate using poly ethylene glycol (PEG1500) as a meltable binder. Methylene blue was used as a model API. Empirical models relating the process variables to the granules properties such as granule mean size, product homogeneity and granule strength were developed using the design of experiment approach. Fluidising air velocity and fluidising air temperature were shown to strongly influence the product properties. Optimisation studies showed that strong granules with homogeneous distribution of the active ingredient can be produced at high fluidising air velocity and at high fluidising air temperatures. 


\section{Introduction}

Size enlargement processes have been extensively used in the pharmaceutical industry to reduce the potential difficulties in the manufacture of solid dosage due to poor compactibilty, compressibility and flowability of many drugs [1]. There are a number of granulation techniques that have been applied such as high shear granulation, twin extrusion and fluidised bed granulation. In an effort to overcome some of the limitations of the conventional process, new granulation techniques are being investigated and developed, among these processes is melt granulation (MG) technique [1].

Melt granulation is a size enlargement process in which powders are agglomerated using low-melting point materials as meltable binders. The meltable binders can be added either as molten liquid or as solid that melts during the process. During the process, heat is continuously applied to maintain molten state of the binder consequently facilitating granule formation. Once the correct size of the granules is achieved the system is cooled to allow solidification of the binder. MG can be performed in a high shear mixer or a fluidised bed unit, with the former being the most common. The process is named in accordance to the type of equipment used, high shear melt granulation (HSMG) or fluidised bed melt granulation (FBMG). There are a number of articles that have been published that look at the effect of process variables in HSMG [2-7]. Similarly several articles which can be found in literature that looks at the effect of process variable on the granule growth kinetics in FBMG. In FBMG binder is sprayed onto a bed of agitated powder. The binder droplets wet the powder particles thereby forming liquid bridges which subsequently solidify to form solid bridges upon cooling. The fluidising temperature, binder spray rate, type of binder, droplet size and binder viscosity have been shown to significantly affect the process [1, 2, 810]. 
Fluidised hot melt granulation (FHMG) is an alternative to FBMG and HSMG; this is a novel process in which granules are produced by mixing low-melting point binders with other excipients and drug directly in fluid bed of hot air. Unlike FBMG and HSMG no spraying system is required. In comparison to other conventional granulation techniques fluidised hot melt granulation offers several advantages $[1,11]$. For instance there is no need to use solvents hence no solvent recovery issues and associated safety and environmental considerations are eliminated. It is a good alternative to wet granulation when dealing with moisture sensitive materials.

In the literature regarding the effect of process and formulation variables of granule homogeneity in high shear granulation, most of these articles identified impeller speed, amount of binder, primary particle size, chopper speed and hydrophobicity of the components as contributors to product homogeneity / heterogeneity [3, 5, 6, 12-18]. Some of the studies on FHGM have been centred on understanding the granulation mechanism [11, 19] and the influence of the process and formulation variables on granule properties like size, growth kinetics and strength $[1,9,10,20,21]$. The subject of product homogeneity in FHGM has received limited attention.

The aim of this research was to study the influence of process variables on API homogeneity of granules produced via fluidised bed melt granulation with a view of optimising the process for product homogeneity. It is not sufficient to have a granular product that is homogeneous in terms of the composition. The mechanical properties of the product are also very important as they influence the post granulation processes and handling [22]. The influence of fluidising air velocity (FAV), fluidising air temperature (FAT) and granulation time on product homogeneity were investigated. 


\section{Materials and Methods}

96

97

98

99

100

101

102

103

104

105

106

107

108

109

110

111

112

\subsection{Materials}

Lactose monohydrate powder, supplied by Sigma Aldrich GmbH, was used as the main excipient. The binder was poly (ethylene glycol) with an average molecular weight of 1500 (81210 Fluka analytical grade), produced and supplied by Sigma Aldrich GmbH, Germany. Methylene Blue (MB) - high purity biological strain, produced and supplied by Sigma Aldrich, was used as a model active ingredient. The lactose powder had mean size $\left(\mathrm{d}_{50}\right)$ of about 50 micrometres. The size of the MB powder particles was less than 75 microns.

\subsection{Granulation Equipment}

A Sherwood Scientific (Mark II) Fluidised Bed Drier was used for granulation of lactose monohydrate, MB and PEG mixture. It consists of a 5 litre glass container with a fine mesh nylon gauze air distributor, stainless steel support gauze and a filter bag at the top of the unit. The inlet air temperature of the granulator can be controlled accurately to $\pm 1{ }^{\circ} \mathrm{C}$.

\subsection{Granule production}

Preliminary experiments were done to find the feasible range of process variables over which it was possible to produce decent granules in the fluidised bed unit. The results showed that granulation time in the range 10 to 20 minutes, blower speed settings between 4 and 6 and bed temperature of between 50 and $60{ }^{\circ} \mathrm{C}$ would be suitable for granule production. The PEG1500 flakes were mashed through a 0.5 and $1.0 \mathrm{~mm}$ sieves. Trial experiments on the suitable binder to solid ratio showed that a ratio of 0.1 was suitable. Each batch was composed of $200 \mathrm{~g}$ of lactose powder, $20 \mathrm{~g}$ of the PEG1500 particles and $200 \mathrm{mg}$ of MB powder. 

the influence of the process variables of the granules properties and variability in API concentrations in the granules and tablets. Design of experiment (DOE) software, Design Expert Version 8 (Stat Easy Inc., USA), was used to produce a list of experiments and to analyse the results. A three level factorial design was used to study the influence of fluidising

122 air velocity, granulation time and bed temperature on the product characteristics. Table 1 shows the process variables that were investigated.

\section{$124 \quad 2.4$ Characterisation of the granules}

\subsubsection{Size analysis}

The granules were then sieved using Retsch sieves on an orbital sample shaker (Stuart

Orbital Shaker, Cole-Parmer, UK) for 5 minutes at speed of 180 rpm. Previous work done by our research group with similar type of granules, showed that at this setting the amount of granule breakage was insignificant. The aperture sizes of the sieves used in the analysis were in the range 500 to $4000 \mu \mathrm{m}$.

131 The mass mean diameter $\left(\bar{d}_{m}\right)$ of the granules was calculated according to;

$$
\bar{d}_{m}=\frac{\sum_{i=1}^{n} m_{i} \bar{x}}{\sum_{i=1}^{n} m_{i}}
$$

133 In Eq. (1) $m_{i}$ is mass of granules in the interval $x_{i}$ to $x_{i+1}$ and $\bar{X}$ is average size of the size

134 class given by $\bar{X}=\frac{\left(x_{i}+x_{i+1}\right)}{2}$. 


\subsubsection{Granule Strength Analysis}

136

137

138

139

150

The strength of granules in the size range 1.4 to $1.7 \mathrm{~mm}$ was determined from compression of a bed of granules in a confined cylindrical die using a method previously described in [23]. The choice of this size range for all the analysis of the granules was based on the availability of the sufficient granules from this class across all batches that were produced. The punch used in the test had a diameter of $9.95 \mathrm{~mm}$ and the dimensions of the die were as follows; internal diameter of $10 \mathrm{~mm}$; external diameter of $22 \mathrm{~mm}$ and height of $10 \mathrm{~mm}$. Work done earlier on similar granules had shown that the granules were strain rate- independent for compression speed ranging from 0.1 to $50 \mathrm{~mm} / \mathrm{min}$. The beds of granules were compressed to a maximum compression force of $500 \mathrm{~N}$ using a compression test speed of $10 \mathrm{~mm} / \mathrm{min}$. The setting of $10 \mathrm{~mm} / \mathrm{min}$ was chosen allowed compression tests to be performed within a reasonable time whilst also provide sufficient data points for the analysis. The force-displacement data obtained during the compression of bed or granules were analysed using a method described previously $[13,24,25]$ to obtain the single granule strength. Equation (2) was fitted to the plot of $\ln P$ versus natural strain to obtain the granule strength parameter.

$\ln P=\ln \left(\frac{\tau}{\alpha}\right)+\alpha \varepsilon+\ln \left(1-e^{-\alpha \varepsilon}\right)$

In Eq. $2 \alpha$ is a pressure coefficient, $\tau$ the Adam's parameter, $P$ is the applied pressure and $\varepsilon$ is the natural strain.

\subsubsection{Determination of API Concentration calibration}

Solutions of different concentrations of the pseudo API ranging from 1 to 20 ppm were produced by dissolving the MB in deionised waster. The absorbance of the resultant solutions at a wavelength of $664 \mathrm{~nm}$ was measured with a spectrophotometer (HACH DR2800, HACH 
Inc, USA). The calibration equation for conversion of absorbance to concentration was obtained from the linear plot and the concentration was correlated to absorbance according to:

$$
C_{M B}=5.1666 A_{664}+0.0358
$$

In Eq. $3 C_{M B}$ is the concentration of the MB solution and $A_{664}$ is the absorbance of the solution at a wavelength of $664 \mathrm{~nm}$. The correlation coefficient, $R^{2}$, of the plot of $c_{\text {мв }}$ versus $A_{664}$ was 0.9991 .

\subsubsection{Composition Analysis of granules}

The distribution of the API across different size of the granules was measured by dissolving a known mass of granules in a known volume of distilled water and measuring the absorbance of the colloid at a wavelength of $664 \mathrm{~nm}$ using a spectrophotometer. The concentration (in ppm) of the colloid was calculated using Eq. 3. The concentration of the MB in dry sample (mg/g) was them determined from;

$$
C_{M B, \text { exp }}\left(x_{i}\right)=C_{M B} \times\left(\frac{m_{M B}}{m_{p}}\right) \times\left(\frac{m_{s}\left(x_{i}\right)}{V}\right)
$$

where $m_{M B}$ is the mass of MB added to the batch; $m_{p}$ is total mass of powder (mass of lactose and solid binder PEG); $m_{s}\left(x_{i}\right)$ mass of sample granules of from size class $x_{i}$ used in measurement; $V$ (in litres) is volume of dissolution medium.

\subsubsection{Composition homogeneity across single size}

Ten random samples of approximately $1 \mathrm{~g}$ of granules in the required size range (1.4 to 1.7 $\mathrm{mm}$ ) were withdrawn from each batch. Colloids were prepared from each of the samples by adding the granules to $25 \mathrm{ml}$ of de-ionised water. The concentration of the methylene blue solution was obtained by measuring the absorbance of the solution at a single wavelength of 
$664 \mathrm{~nm}$ and calculating the concentration from the previously determined calibration equation. For each batch the coefficient of variation was calculated using [13, 23];

$\kappa=\frac{\bar{\sigma}}{\hat{C}}$

Eq. 5

where $\hat{C}$ is the mean of the samples and $\bar{\sigma}$ is the standard deviation of methylene blue concentration in the samples;

The homogeneity coefficient, $\eta$, was then defined as;

$\eta=1-\kappa$

Eq. 6

where $\kappa$ is as defined in Eq. 5 and $0 \leq \eta \leq 1$. Homogeneity coefficient of 1 corresponds to a completely homogeneous distribution of the pseudo active ingredient while a low value of $\eta$ indicates poor distribution.

\section{Results \& Discussion}

Table 2 summarises the results of mean granule size, granules strength and coefficient of variation of the API in the granules in the size range 1.4 to $1.7 \mathrm{~mm}$.

\subsection{Preliminary results}

The effect of powder binder particle size on the size distribution of the granules was investigated by granulating lactose powder with the PEG binder of different sizes; flakes as received, flakes grated through the $0.5 \mathrm{~mm}$ sieve, and flakes grated through $1.0 \mathrm{~mm}$ sieve. The other granulation conditions such as granulation time and fluidising air velocity were kept constant at 15 minutes and $2.25 \mathrm{~m} / \mathrm{s}$ respectively. The cumulative size distribution 
curves and the plot of granule median size for the different flake particle sizes are shown in Fig. 1. It is clear from these results that the final granule size is strongly influenced by the size of the binder particle. Increasing the size of the particle increases the granule median size. The PEG particles melt as the temperature of the bed increases creating nuclei for granule growth. The size of nuclei formed depends on the size of PEG flake particles, larger flake particle result in formation of large nuclei which is then translated to the size of the granules formed.

\subsection{MB distribution}

The subject of inhomogeneity of drug and binder across different size has received a lot of attention in literature [13, 16, 26-31]. Several possible causes of drug inhomogeneity have been discussed namely difference in the particle sizes of constituents, different in solubility [32] and migration of the drug particles [33]. It has been shown by numerous researchers that primary particle size plays an important role in determining the product homogeneity. If the particle size distributions of the starting materials are similar then a homogeneous product is expected. It was observed that granulation involving drugs with finer particle sizes compared to filler material resulted in a product were the smaller granules would be super potent [34]. However the opposite is observed if the drug particles are coarser than the filler the larger granules would be super-potent [26, 35]. A typical distribution of the MB across different sizes of granules is depicted in Fig. 2. This shows that distribution is bimodal with the peaks around $0.3 \mathrm{~mm}$ and $1.5 \mathrm{~mm}$. It also shows that granules larger than $2 \mathrm{~mm}$ have lower $\mathrm{MB}$ content. The average concentration of MB in the granules across all sizes is shown in Fig. 3. It is evident from the figure that some of the granules are richer in the $\mathrm{MB}$ compared to the other granules, for instance for batch 1 granules in the size ranges 0.5 to $0.6 \mathrm{~mm}$ and 1.7 to $2.0 \mathrm{~mm}$ had concentration above the theoretical expected value of $\sim 0.91 \mathrm{mg} / \mathrm{g}$. 


\subsection{Effect of process variables on granule size and size distributions}

222

223

The effect of process variable on the size distribution of the granules was investigated from granulation of lactose monohydrate powder, PEG 1500 (particle size $<1 \mathrm{~mm}$ ) and methylene blue. The granules mean sizes for the different batches obtained using Eq.1 are presented in Table 2. The granule mean sizes were ranging from about 0.85 to $1.88 \mathrm{~mm}$. The minimum granule mass mean diameter was obtained in Batch 6 when the fluidised bed temperature, fluidising air velocity and granulation time were $50{ }^{\circ} \mathrm{C}, 2.45 \mathrm{~m} / \mathrm{s}$ and 20 minutes respectively. The maximum was obtained in Batch 5 when the fluidised bed temperature, fluidising air velocity and granulation time were $60{ }^{\circ} \mathrm{C}, 2.03 \mathrm{~m} / \mathrm{s}$ and 20 minutes respectively.

The typical size distribution curves for these two batches of experiments are shown in Fig. 4. It is quite evident that Batch 6 has lower fraction of large granules, and a large fraction of granules less with an equivalent diameter less than $1.7 \mathrm{~mm}$.

A summary of the statistical analysis of the effect of the granulation process variables is given in the ANOVA table presented in Table 3.

The granule mass mean size can be written in terms of the coded process variables $A, B$, and $\mathrm{C}$ representing the temperature, fluidisation air velocity and granulation time respectively. This is given as;

$d_{\text {mean }}=+1.06+0.21 A-0.21 B+3.84 \times 10^{-3} C+0.22 A C-0.15 B C$ Eq. 7

According to Eq.7 all three process variable significantly affect the mean size of granules produced by fluidised bed hot melt granulation. Judging from the coefficient of A and B in Eq. 7, the relative contribution of the fluidising air velocity and fluidised bed temperature to the granule mean size is almost of similar scale. Granulation time has slightly less effect on 
the mean granule size. However the interaction between granulation time and fluidised bed temperature is also very strong as can be noted from the high coefficient values of the $A * C$ term.

The granule mass mean size can also be written in terms of the actual process variables as;

$$
d_{\text {mean }}=+2.626-0.0925 \theta+1.575 U-0.102 t+8.91 \times 10^{-3} \theta t+0.173 U t
$$

Eq. 8

In Eq. $8 U$ is the fluidising air velocity, $\theta$ is the fluidised bed temperature and $t$ is the granulation time.

To visualise the effect of the process variable on the granule mass mean size Eq. 8 was used to calculate the granule mass mean size for various combinations of fluidising bed temperature, fluidised air velocity and granulation times and presented in form of mesh plots (Fig. 5). Fig. 5 shows the effect of varying both the fluidising air velocity and fluidised air temperature on the granule mass mean size whilst maintaining the granulation time constant at 20 minutes. Increasing the temperature from $50{ }^{\circ} \mathrm{C}$ to $60{ }^{\circ} \mathrm{C}$ has an effect of increasing the granule mass mean size. This increase in granule size may be attributed to increase in the number of binder droplets formed due to melting of the binder at higher temperatures. The increase in the number of droplets increases the chances of bond formation between the powder primary particles. The interesting point to note is that the relative change in the size of granulation with respect to change in temperature is lower at higher fluidising air velocities. At higher fluidising air velocities increased loss of binder by evaporation which effects the bond formation; less binder becomes available for bond formation. This trend is similar to earlier reports in literature of fluidised bed wet granulation [20, 36, 37]. According to previous work, higher fluidising air velocity favours loss of binder through evaporation [37], however in the work reported here the amount of binder lost in this way would be 
insignificant since the binder hardly evaporates at the fluidised temperature investigated here.

267 Their results show that slower granule growth rate was obtained at higher fluidising air velocity compared to what was obtained at lower velocities. It was postulated that decreasing the fluidising air velocity would increase the probability of contact between wetted particles. On the contrary in another separate study [38], increasing fluidised air velocity was found to increase the mean size of the granules. In this study the moisture content level was maintained at the same value. The increase in the mean granule size could be attributed higher bed expansion observed at higher fluidising air velocity. This might have resulted in an increase in the probability in granule formation as the bed expansion reduced the separation between the spray zone and bed.

Fig. 5 also shows the effect of changing the granulation time on the granule mass mean size. This figure illustrates that at shorter granulation times the effect of fluidising air velocity and fluid bed temperature on the granulation size is less pronounced; the granule mass mean size is roughly $1.0 \mathrm{~mm}$. The effect of these two variables become significant as the granulation time is increased; the rate of increase of size with respect to temperature increases whilst the rate of change of the size with respect to air velocity also becomes more evident.

\subsection{Effect of process variables on granule homogeneity}

The statistical analysis (ANOVA) of the results on the effect of the process variables on the drug homogeneity of the samples taken from granules in the size range 1.4 to $1.7 \mathrm{~mm}$ is presented in Table 4. According to results present in Table 4 the model adequately describes the data $(p$-value $=0.0005)$. The process variables namely; fluidising air velocity, fluidised bed temperature and granulation time, are important in determining the homogeneity of the drug in the granules studied. The interaction between the fluidised bed temperature and granulation time is also strong. 

determined from statistical analysis of the data. The effect of the uniformity coefficient is related to the coded process variables according to; process variables the uniformity coefficient equation reduces to;

296

$$
\eta=\left[0.488+5.50 \times 10^{-3} \theta+0.0879 U+0.0261 t-5.30 \times 10^{-4} \theta t\right]^{\frac{1}{3}}
$$

All the symbols are as defined previously. shown in in Fig. 6. The surface plot shows that increasing the speed of the fluidising air velocity results in improvement in the homogeneity of the granules; the homogeneity coefficient increase from 0.97 to around 0.99 when the granulation temperature is $50{ }^{\circ} \mathrm{C}$. It can also be noted that at this temperature the granulation time has little influence on the homogeneity coefficient. However when the fluidising air temperature is set at $60^{\circ} \mathrm{C}$ the influence of the temperature on the homogeneity factor becomes more significant; shorter granulation time favours better homogeneity.

Increasing the fluidising air velocity can result in more breakage of the agglomerates which manifests as reduction in the growth rate $[9,10]$ or a reduction in average granule size [38-40]. It has been reported in literature that breakage of particles during the granulation process promotes material exchange between the granules which improves product homogeneity $[15,16]$. It would then be logical to expect an increase in the homogeneity of the product as the fluidising air velocity is increased. This is illustrated in Fig. 6 where 
increasing the fluidising air velocity is shown to result in an increase in the homogeneity coefficient. According to Fig. 6 the influence of fluidising air on the homogeneity is more pronounce at high temperature than at lower temperatures. Within the design space studied in this work reasonably high level of homogeneity were achieved despite the fact that pseudo active ingredient was added as a solid and very low proportion.

\subsection{Effect of process variables on granule strength}

Another important aspect to look at when analysing the homogeneity of the granules is the strength of the granules. The influence of the processing conditions on the strength of then granules was also investigated in this work and an empirical equation relating the granule strength determined from confined compression test of bed of granules as described in Section 2.5. Within the range of the process variables studied here, the FAV and FAT were found to strongly affect the strength of the granules. The statistical analysis of the results is summaries in ANOVA table presented in Table 5 show that chosen model is suitable for describing the data obtained in the experiments (p-value $=0.0137$ ). The FAV, with an associated p-value of 0.0055 , is the most important variable affecting the strength of the granules. The granulation time was found not to be an important factor on the strength of the granule. There is also strong interaction between FAV and FAT (p- value $=0.0346$ ).

The granule strength, $\tau$, is related to the process conditions according the empirical equation;

In Eq.11 the symbols $\theta$ and $U$ are as defined previously. The empirical equation predicts that the granule strength decreases with increasing values of fluidising air velocity and fluidising air temperature. The surface plot shown in Fig. 7 shows the effect of fluidising 
357

air velocity and fluidising air temperature on granule strength. The figure shows that the highest granule strength was obtained at high fluidising air temperature and high fluidising air velocity. The interaction effects between the fluidising air velocity and air temperature is quite evident in Fig. 7. It is clear that the influence of fluidising air temperature on granule strength depends on fluidising air velocity; at low fluidising air velocity increasing the temperature of the bed does not result in an increasing in the strength of the granules as seen at high fluidising air velocity.

\subsection{Optimisation}

One of the important uses of the experimental design is process optimisation. In this case the empirical model developed from design of experiments, was used to predict the process conditions that can used to produce granules with desired attributes. Here the DOE was used to predict optimum process and formulation variables that are required to produce granules with suitable strength and with the highest level of homogeneity. The granule should be strong enough to survive stringent forces that they experience during transportation and handling. The criteria used to determine the process conditions is summarised in Table 6 . Different weighting was ascribed to the different input variables and the response variables. It is shown in Table 6 that all the process variables were assigned equal importance with a default weighting of 3 . It is important that the granules produced would have sufficient strength for handling during post granulation processes and is also equally important they have homogeneous distribution of the API; hence these two granule attributes were given high weighting during the optimisation.

The desirability objective function is given by [41];

$D=\left(d_{1}^{r_{1}} \times d_{1}^{r_{2}} \times \ldots \times d_{1}^{r_{n}}\right)^{\frac{1}{\Sigma r_{j}}}=\left(\prod_{j=1}^{n} d_{j}^{r_{j}}\right)^{\frac{1}{\Sigma r_{j}}}$ 
In the above equation $r_{j}$ is degree of importance and $d_{1}$ is the desirability factor of variable. Importance $\left(r_{\mathbf{i}}\right)$ varies from the least important a value of 1 , to the most important a value of 5. Detailed description of the models and equations can be found elsewhere [41, 42].

Desirability plot for the design space is shown in Fig. 8. The plot shows that the highest desirability of about 0.94 is achieved at the highest temperature and fluidising air velocity. A high value (close to 1) of the desirability functions indicates that constraints for the optimisation of response functions are being closely satisfied. As can be seen in Fig. 8 the values of desirability approach a value of 1 as the fluidising air velocity is increased and highest values are achieved when both fluidising air velocity and bed temperature are high. This result means that constraints set up for the optimisation are closely matched when fluidising air flow rate and bed temperature are both high. The summary of conditions for formation of strongest granules with highest homogeneity is given in Table 7 . This table shows that granules with optimum attributes can be obtained with a granulation time of 11.37 minutes at fluidising bed temperature of $60{ }^{\circ} \mathrm{C}$ with fluidising air velocity of $2.45 \mathrm{~m} / \mathrm{s}$. The expected mean size of the granules is about $1 \mathrm{~mm}$ and strength of granules will be around 3.31 MPa. The homogeneity coefficient of the granules is 0.9895 which is close to unit.

\section{Conclusion}

It can be concluded from the work presented here that within the range of operation variables investigated in this work high levels of homogeneity of the API in the granules could be achieved through fluidised bed hot melt granulation. Whereas granulation time had little influence on the granule homogeneity, fluidising air velocity and fluidised air temperature had a strong influence. It is postulated that increasing the fluidising air velocity increases breakage of granules due to increased frequency of granule to granule collision and 
381 collision with the other component of the granulator. This increase in breakage results in the 382 formation of a more homogeneous product. Fluidising air temperature is thought to influence 383 the availability of binder for agglomeration process. Rate of formation of nuclei should 384 increase as the temperature of the bed is increased to levels above the melting point of the 385 binder. The viscosity of the binder droplets formed when the PEG particles melt should 386 decreases with increasing fluidised bed temperature. The strength of the nuclei formed is also 387 a function of binder viscosity; increasing the viscosity increases the strength and opposite is 388 observed as the viscosity is decreased. It is also known that breakage is a function of strength 389 of the nuclei therefore it would then be logical to expect the rate of breakage of the nuclei to 390 be high at higher temperatures. Hence high fluidised bed temperature would be expected to 391 enhance product homogeneity as observed.

\section{Acknowledgement}

This research was funded through the School of Chemistry and Chemical Engineering, 394 departmental research funding (DRC) for which the authors are truly indebted. 


\section{References}

397 [1] H. Zhai, S. Li, D.S. Jones, G.M. Walker, G.P. Andrews, The effect of the binder size and viscosity on agglomerate growth in fluidised hot melt granulation, Chemical Engineering Journal, 164 (2010) 275-284.

[2] M. Kidokoro, K. Sasaki, Y. Haramiishi, N. Matahira, Effect of Crystallization Behavior of Polyethylene Glycol 6000 on the Properties of Granules Prepared by Fluidized Hot-Melt Granulation (FHMG), Chemical and Pharmaceutical Bulletin, 51 (2003) 487-493. [3] L. Ochoa, M. Igartua, R.M. Hernandez, A.R. Gascon, J.L. Pedraz Munoz, Preparation of sustained release hydrophilic matrices by melt granulation in a high-shear mixer, Journal of Pharmacy and Pharmaceutical Sciences, 8 (2005) 132-140.

[4] N. Rahmanian, M. Ghadiri, X. Jia, Seeded granulation, Powder Technology, 206 (2011) 53-62.

[5] G.K. Reynolds, C.A. Biggs, A.D. Salman, M.J. Hounslow, Non-uniformity of binder distribution in high-shear granulation, Powder Technology, 140 (2004) 203-208.

[6] A.C. Scott, M.J. Hounslow, T. Instone, Direct evidence of heterogeneity during highshear granulation, Powder Technology, 113 (2000) 205-213.

[7] C. Mangwandi, L. JiangTao, A.B. Albadarin, S.J. Allen, G.M. Walker, Alternative method for producing organic fertiliser from anaerobic digestion liquor and limestone powder: High Shear wet granulation, Powder Technology, 233 (2013) 245-254.

[8] T. Abberger, A. Seo, T. Schaer, The effect of droplet size and powder particle size on the mechanisms of nucleation and growth in fluid bed melt agglomeration, International Journal of Pharmaceutics, 249 (2002) 185-197.

[9] H.S. Tan, A.D. Salman, M.J. Hounslow, Kinetics of fluidized bed melt granulation II: Modelling the net rate of growth, Chemical Engineering Science, 61 (2006) 3930-3941. [10] H.S. Tan, A.D. Salman, M.J. Hounslow, Kinetics of fluidised bed melt granulation I: The effect of process variables, Chemical Engineering Science, 61 (2006) 1585-1601. [11] G.M. Walker, S.E.J. Bell, G. Andrews, D. Jones, Co-melt fluidised bed granulation of pharmaceutical powders: Improvements in drug bioavailability, Chemical Engineering Science, 62 (2007) 451-462.

[12] Z. Belohlav, L. Brenkova, J. Hanika, P. Durdil, P. Rapek, V. Tomasek, Effect of Drug Active Substance Particles on Wet Granulation Process, Chemical Engineering Research and Design, 85 (2007) 974-980.

[13] C. Mangwandi, L. JiangTao, A.B. Albadarin, S.J. Allen, G.M. Walker, The variability in nutrient composition of Anaerobic Digestate granules produced from high shear granulation, Waste Management, 33 (2013) 33-42.

[14] T.H. Nguyen, W. Shen, K. Hapgood, Effect of formulation hydrophobicity on drug distribution in wet granulation, Chemical Engineering Journal, 164 (2010) 330-339.

[15] K. van den Dries, O.M. de Vegt, V. Girard, H. Vromans, Granule breakage phenomena in a high shear mixer; influence of process and formulation variables and consequences on granule homogeneity, Powder Technology, 133 (2003) 228-236.

[16] K. van den Dries, H. Vromans, Relationship between inhomogeneity phenomena and granule growth mechanisms in a high-shear mixer, International Journal of Pharmaceutics, 247 (2002) 167-177.

[17] R. Kinget, R. Kemel, Preparation and properties of granulates containing solid dispersions, Acta Pharmaceutica Technologica, 31 (1985) 57-62.

[18] C. Mangwandi, M.J. Adams, M.J. Hounslow, A.D. Salman, Influence of fill factor variation in high shear granulation on the post granulation processes: Compression and tablet properties, Powder Technology, 263 (2014) 135-141. 

fluidised hot melt granulation, Powder Technology, 189 (2009) 230-237. [20] H.S. Tan, A.D. Salman, M.J. Hounslow, Kinetics of fluidised bed melt granulation: IV. Selecting the breakage model, Powder Technology, 143-144 (2004) 65-83. [21] H.S. Tan, A.D. Salman, M.J. Hounslow, Kinetics of fluidised bed melt granulation III: Tracer studies, Chemical Engineering Science, 60 (2005) 3835-3845.

[22] C. Mangwandi, M.J. Adams, M.J. Hounslow, A.D. Salman, An investigation of the influence of process and formulation variables on mechanical properties of high shear granules using design of experiment, International Journal of Pharmaceutics, 427 (2012) 328336.

[23] C. Mangwandi, M.J. Adams, M.J. Hounslow, A.D. Salman, Effect of batch size on mechanical properties of granules in high shear granulation, Powder Technology, 206 (2011) 44-52.

[24] M.J. Adams, M.A. Mullier, J.P.K. Seville, Agglomerate strength measurement using a uniaxial confined compression test, Powder Technology, 78 (1994) 5.

[25] C. Mangwandi, M.J. Adams, M.J. Hounslow, A.D. Salman, Effect of impeller speed on mechanical and dissolution properties of high-shear granules, Chemical Engineering Journal, 164 (2010) 305-315.

[26] C. Bacher, P.M. Olsen, P. Bertelsen, J.M. Sonnergaard, Granule fraction inhomogeneity of calcium carbonate/sorbitol in roller compacted granules, International Journal of Pharmaceutics, 349 (2008) 19-23.

[27] D. Ely, S. Chamarthy, M.T. Carvajal, An investigation into low dose blend uniformity and segregation determination using NIR spectroscopy, Colloids and Surfaces A: Physicochemical and Engineering Aspects, 288 (2006) 71-76.

[28] T. Kapsidou, I. Nikolakakis, S. Malamataris, Agglomeration state and migration of drugs in wet granulations during drying, International Journal of Pharmaceutics, 227 (2001) 97-112. [29] S. Karami, M. Imani, F. Farahmandghavi, A novel image analysis approach for evaluation of mixing uniformity in drug-filled silicone rubber matrix, International Journal of Pharmaceutics, 460 (2014) 158-164.

[30] G. Leonard, F. Bertrand, J. Chaouki, P.M. Gosselin, An experimental investigation of effusivity as an indicator of powder blend uniformity, Powder Technology, 181 (2008) 149159.

[31] Y. Sulub, R. LoBrutto, R. Vivilecchia, B.W. Wabuyele, Content uniformity determination of pharmaceutical tablets using five near-infrared reflectance spectrometers: A process analytical technology (PAT) approach using robust multivariate calibration transfer algorithms, Analytica Chimica Acta, 611 (2008) 143-150.

[32] J.E. Ojile, C.B. Macfarlane, A.B. Selkirk, Drug distribution during massing and its effect on dose uniformity in granules, International Journal of Pharmaceutics, 10 (1982) 99-107. [33] A.B. Selkirk, The effect of solute migration on the distribution of borax throughout a batch of granules, Journal of Pharmacy and Pharmacology, 28 (1976) 512-514.

[34] H. Egermann, W. Reiss, Effect of particle size of drug and diluent on drug distribution in granule size fractions, Acta Pharmaceutical Technology, 34 (1988) 5S.

[35] H. Vromans, H.G.M. Poels-Janssen, H. Egermann, Effects of High-Shear Granulation on Granulate Homogeneity, Pharmaceutical development and technology, 4 (1999) 297-303.

[36] U. Arena, M. D'Amore, L. Massimilla, Carbon attrition during the fluidized combustion of a coal, AIChE Journal, 29 (1983) 40-49.

[37] M. Hemati, R. Cherif, K. Saleh, V. Pont, Fluidized bed coating and granulation: Influence of process-related variables and physicochemical properties on the growth kinetics, Powder Technology, 130 (2003) 18-34. 
[38] H. Kokubo, H. Sunada, Effect of Process Variables on the Properties and Binder Distribution of Granules Prepared in a Fluidized Bed, Chemical \& pharmaceutical bulletin, 45 (1997) 1069-1072.

496 [39] S.S. Behzadi, J. Klocker, H. Huttlin, P. Wolschann, H. Viernstein, Validation of fluid bed granulation utilizing artificial neural network, International Journal of Pharmaceutics,

$498 \quad 291$ (2005) 139-148.

499 [40] C. Mangwandi, Fluidised Bed Granulation: Influence of process variables, Department 500 of Chemical and Process Engineering, University of Sheffield, Sheffield, UK, 2004, pp. 175. 501 [41] R.H. Myres, D.C. Montgomery, Responce Surface Methodology, 2nd ed., John WIley \& 502 Sons, New York, 2002.

503 [42] L. Vera Candioti, M.M. De Zan, M.S. Cámara, H.C. Goicoechea, Experimental design 504 and multiple response optimization. Using the desirability function in analytical methods 505 development, Talanta, 124 (2014) 123-138. 
510 Table 1: Summary of process variables and their range of values.

511 Table 2: Effect of process conditions: temperature, air velocity and granulation on size,

512 strength and homogeneity coefficient.

513 Table 3: ANOVA analysis for the selected factorial model for granules median size.

514 Table 4: ANOVA for selected factorial model for uniformity coefficient of active ingredient.

515 Table 5: ANOVA for selected factorial model for granule strength.

516 Table 6: Summary for optimisation criteria

517 Table 7: Summary of process conditions giving the optimum granule characteristics.

\section{List of Figures}

520 Fig. 1: Effect of binder particle size on granule mean size.

521 Fig. 2: Typical MB content distribution across different granule sizes. Results from Batch 10;

522 Experimental conditions; fluidising air velocity: $2.45 \mathrm{~m} / \mathrm{s}$; fluidising air temperature; $60{ }^{\circ} \mathrm{C}$

523 and Granulation time 10 minutes.

524 Fig. 3: Variation of the MB concentration in granules.

525 Fig. 4: Comparison of granule size distributions of two different batches

526 Fig. 5: Surface plot showing effect of fluidising air velocity and fluidised bed temperature on

527 the granule mass mean size for different granulation times.

528 Fig. 6: Effect of fluidising velocity and bed temperature on the granule homogeneity for three

529 different processing times.

530 Fig. 7: Effect of process variables on the granule strength. Granules used in the test were in 531 the size range 1.4 to $1.7 \mathrm{~mm}$.

532 Fig. 8: Desirability plot. 
534 Table 1: Summary of process variables and their range of values.

\begin{tabular}{lccc}
\hline Variable & Level & \\
& Low $(-1)$ & Medium $(0)$ & High $(+1)$ \\
\hline Blower Speed Setting & 4 & 5 & 6 \\
Fluidising Air Velocity $(\mathrm{m} / \mathrm{s})$ & 2.04 & 2.25 & 2.45 \\
Fluidising Air Temperature $\left({ }^{\circ} \mathrm{C}\right)$ & 50 & 55 & 60 \\
Granulation Time (min) & 10 & 15 & 20 \\
\hline
\end{tabular}

535

536

537

538

539

540

541

542 


\begin{tabular}{|c|c|c|c|c|c|c|}
\hline No. & $\theta\left({ }^{\circ} \mathrm{C}\right)$ & $U\left(\mathrm{~ms}^{-1}\right)$ & $t(\min )$ & $d_{\text {mean }}(m m)$ & $\tau(\mathrm{MPa})$ & $\eta(-)$ \\
\hline 1 & 50 & 2.03 & 20 & 0.99 & 1.73 & 0.9766 \\
\hline 2 & 55 & 2.25 & 15 & 1.09 & 1.15 & 0.9802 \\
\hline 3 & 60 & 2.03 & 10 & 1.06 & 1.28 & 0.9791 \\
\hline 4 & 55 & 2.25 & 15 & 1.12 & 1.53 & 0.9829 \\
\hline 5 & 60 & 2.03 & 20 & 1.88 & 0.68 & 0.9551 \\
\hline 6 & 50 & 2.45 & 20 & 0.85 & 2.62 & 0.9881 \\
\hline 7 & 50 & 2.03 & 10 & 1.11 & 1.76 & 0.9786 \\
\hline 8 & 60 & 2.45 & 20 & 1.07 & 2.85 & 0.9735 \\
\hline 9 & 55 & 2.25 & 15 & 1.11 & 2.78 & 0.9841 \\
\hline 10 & 60 & 2.45 & 10 & 1.10 & 3.67 & 0.9894 \\
\hline 11 & 55 & 2.25 & 15 & 1.03 & 3.10 & 0.9852 \\
\hline 12 & 55 & 2.25 & 15 & 1.10 & 2.36 & 0.9835 \\
\hline 13 & 50 & 2.45 & 10 & 1.033 & 1.83 & 0.9887 \\
\hline
\end{tabular}


548 Table 3: ANOVA analysis for the selected factorial model for granules median size.

\begin{tabular}{|c|c|c|c|c|c|}
\hline Source & $\mathbf{S S}^{\mathrm{a}}$ & $\mathbf{D F}^{\mathbf{b}}$ & MS $^{\mathrm{c}}$ & F-value & p-value \\
\hline Model & 0.61 & 5 & 0.120 & 71.48 & $<0.0001$ \\
\hline$A-F A T$ & 0.240 & 1 & 0.240 & 99.36 & $<0.0001$ \\
\hline$B-F A V$ & 0.250 & 1 & 0.250 & 105.14 & $<0.0001$ \\
\hline$C-t$ & $8.32 \times 10^{-5}$ & 1 & $8.32 \times 10^{-5}$ & 0.047 & 0.8351 \\
\hline$A C$ & 0.28 & 1 & 0.28 & 159.18 & $<0.0001$ \\
\hline$B C$ & 0.18 & 1 & 0.18 & 101.10 & $<0.0001$ \\
\hline Residual & 0.011 & 6 & $1.758 \times 10^{-3}$ & & \\
\hline Lack of fit & $5.506 \times 10^{-3}$ & 2 & $2.522 \times 10^{-3}$ & 1.83 & 0.2724 \\
\hline Pure Error & $5.506 \times 10^{-3}$ & 4 & $1.377 \times 10^{-3}$ & & \\
\hline Cor Total & 0.62 & 11 & & & \\
\hline $\begin{array}{l}\text { Std. Dev. } \\
\text { Mean } \\
\text { PRESS }^{1}\end{array}$ & & & $\begin{array}{l}042 \\
1.13 \\
T / A\end{array}$ & & $R^{2}=0.9835$ \\
\hline
\end{tabular}


560 Table 4: ANOVA table for selected factorial model for uniformity coefficient.

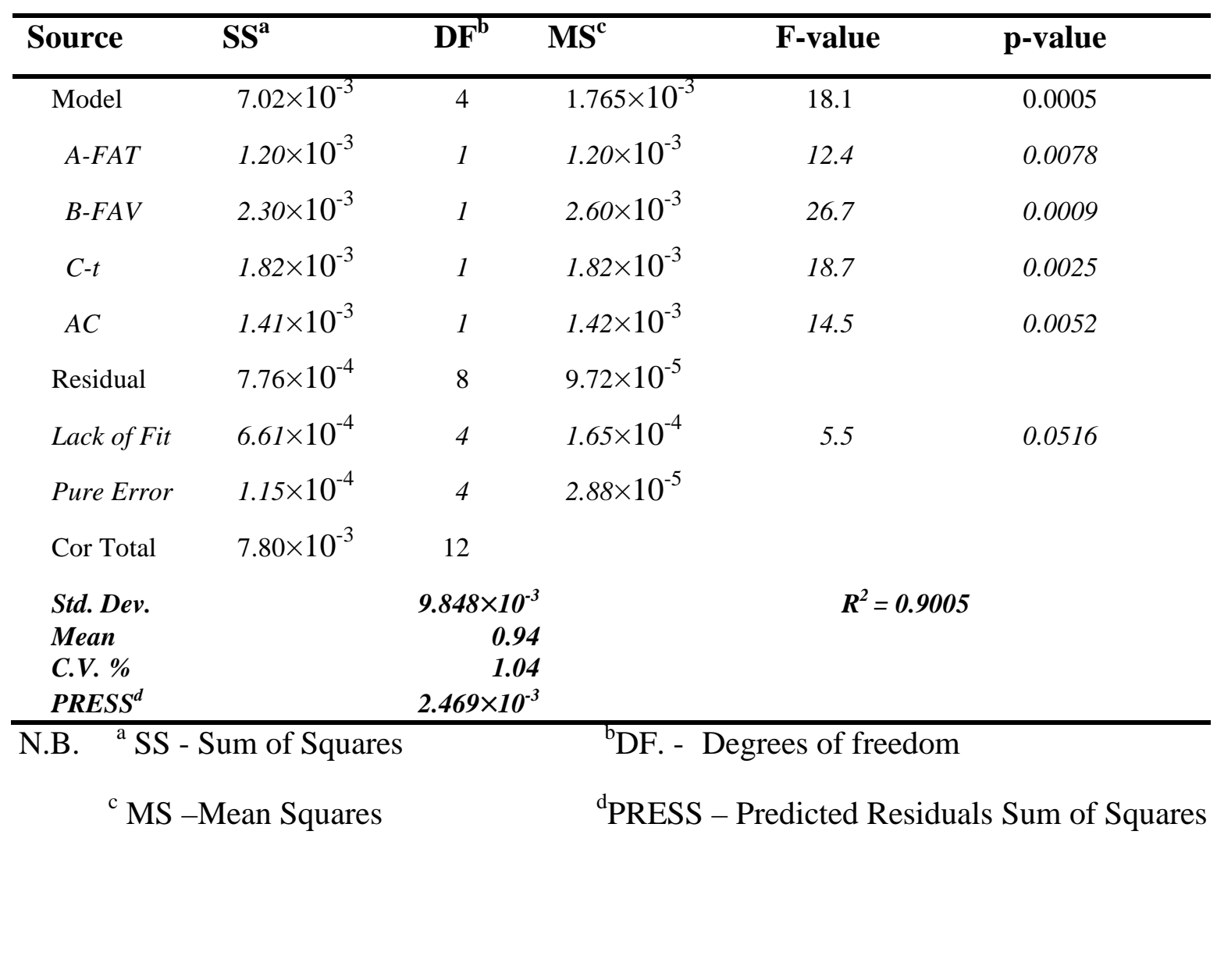


Table 5: ANOVA for selected factorial model for granule strength.

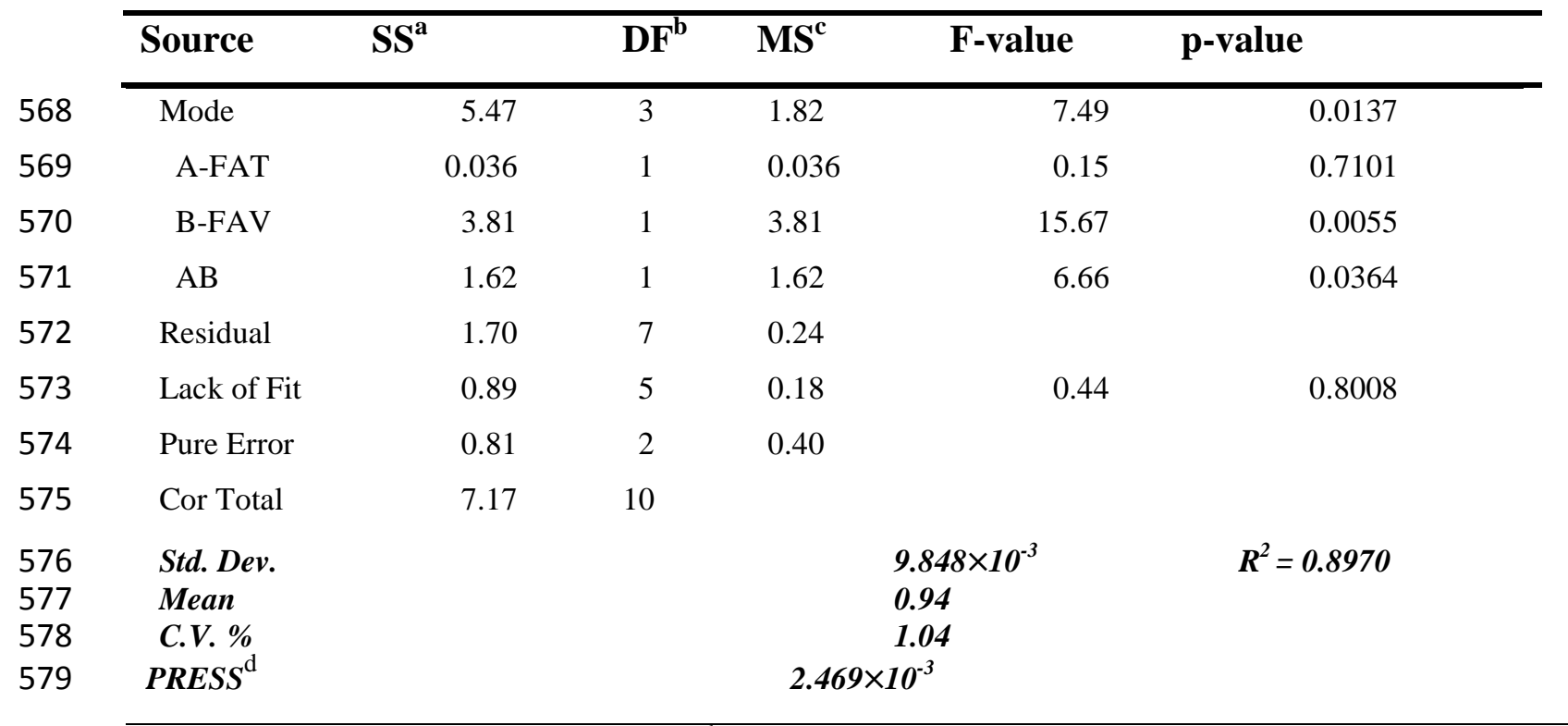

580 N.B. ${ }^{\mathrm{a}}$ SS - Sum of Squares $\quad{ }^{\mathrm{b}} \mathrm{DF}$ - Degrees of freedom

$581 \quad{ }^{\mathrm{c}} \mathrm{MS}$-Mean Squares $\quad{ }^{\mathrm{d}}$ PRESS - Predicted Residuals Sum of Squares

582

583

584

585

586

587

588 
Table 6: Summary for optimisation criteria

\begin{tabular}{llccc}
\hline Name & Goal & Limit & Limit & Importance \\
\hline Process variables & & & & \\
Granulation Time (min) & is in range & 10 & 20 & 3 \\
Fluidizing Air Velocity $(\mathrm{m} / \mathrm{s})$ & is in range & 2.03 & 2.45 & 3 \\
$\quad$ Fluidized Bed Temperature $\left({ }^{\circ} \mathrm{C}\right)$ & is in range & 50 & 60 & 3 \\
Granule attributes & & & & \\
$\quad$ Homogeneity coefficient $(-)$ & maximize & 0.9735 & 0.9999 & 4 \\
Granule strength (MPa) & is in range & 0.68 & 3.67 & 4 \\
Granule mean size $(\mathrm{mm})$ & is in range & 1.00 & 1.5 & 3 \\
\hline
\end{tabular}

590

591

592 
594 Table 7: Summary of process conditions giving the optimum granule characteristics.

\begin{tabular}{ccc}
\hline & Value & Units \\
\hline Process conditions & & \\
Granulation Time & 11.31 & Min \\
Fluidising Air Velocity & 2.45 & $\mathrm{~m} / \mathrm{s}$ \\
Fluidised Bed Temperature & 60 & ${ }^{\circ} \mathrm{C}$ \\
Granule Attributes & & \\
Homogeneity Coefficient & 0.9898 & - \\
Granule Strength & 3.31 & $\mathrm{MPa}$ \\
Granule mean size & 1.004 & $\mathrm{~mm}$ \\
\hline
\end{tabular}

595

596

597 


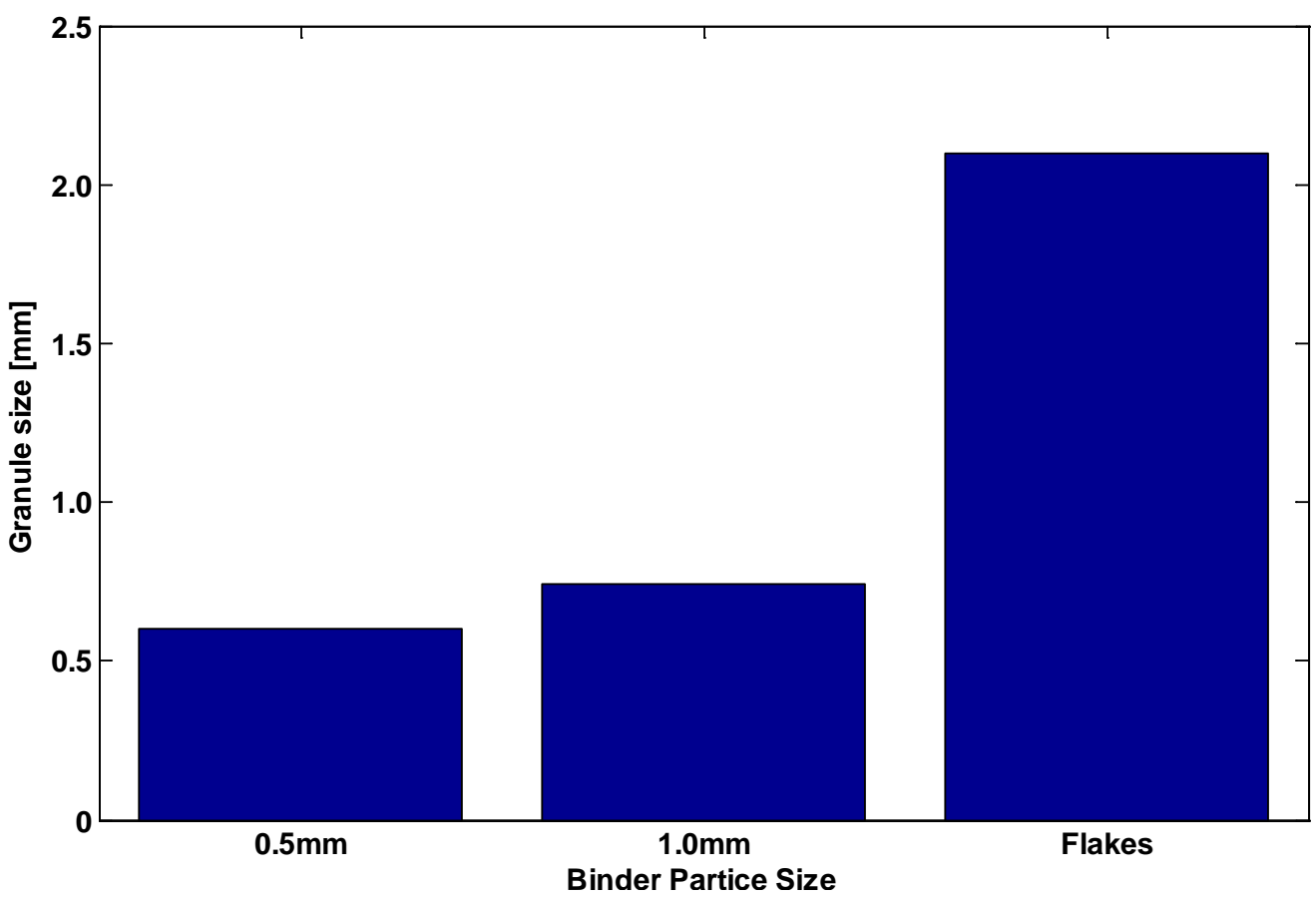

601 Fig. 1: Effect of binder particle size on granule mean size.

602 


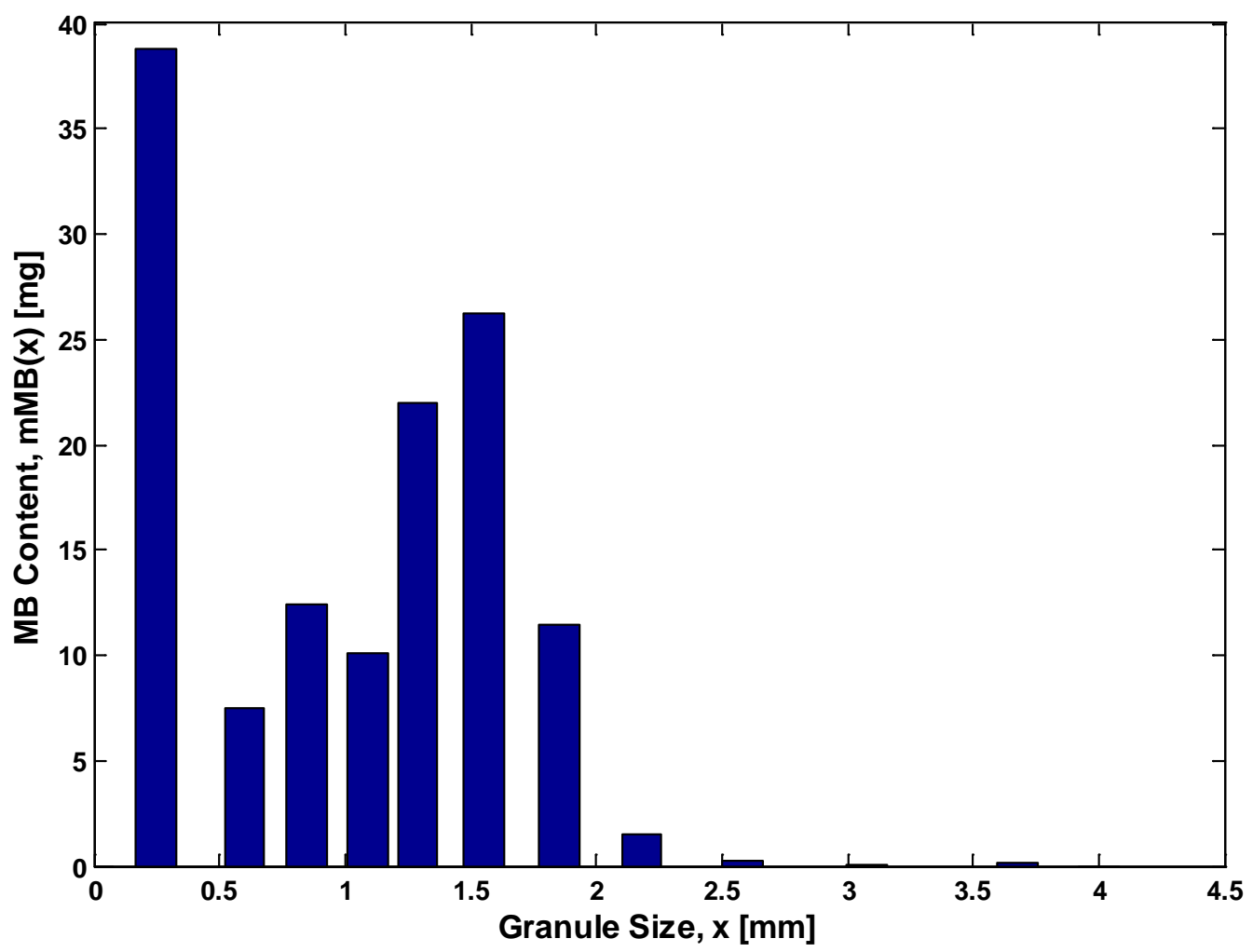

604

Fig. 2: Typical MB content distribution across different granule sizes. Results from Batch 10; Experimental conditions; fluidising air velocity: $2.45 \mathrm{~m} / \mathrm{s}$; fluidising air temperature; $60{ }^{\circ} \mathrm{C}$ and Granulation time 10 minutes. 


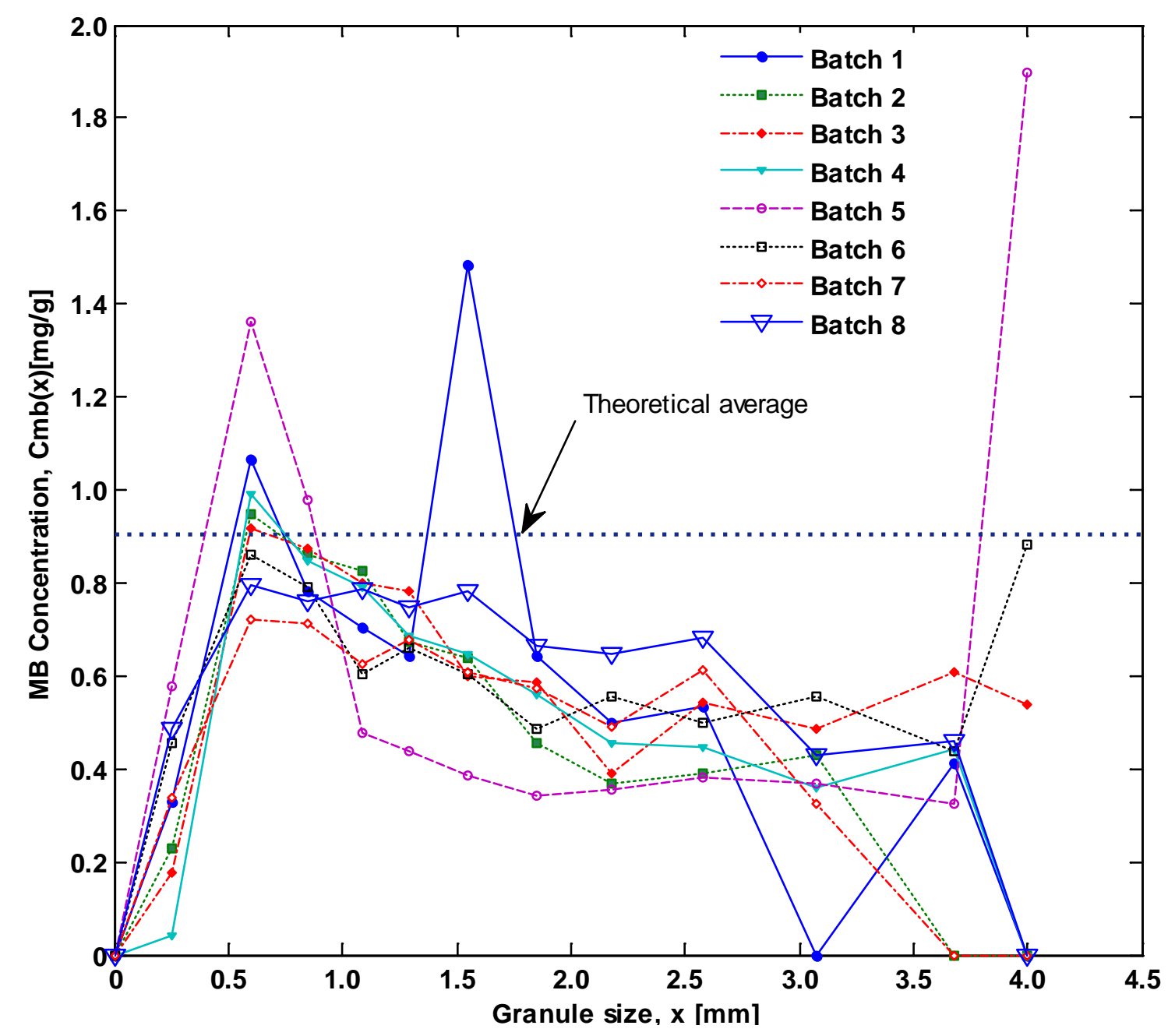

608

609

Fig. 3: Variation of the MB concentration in granules.

610 


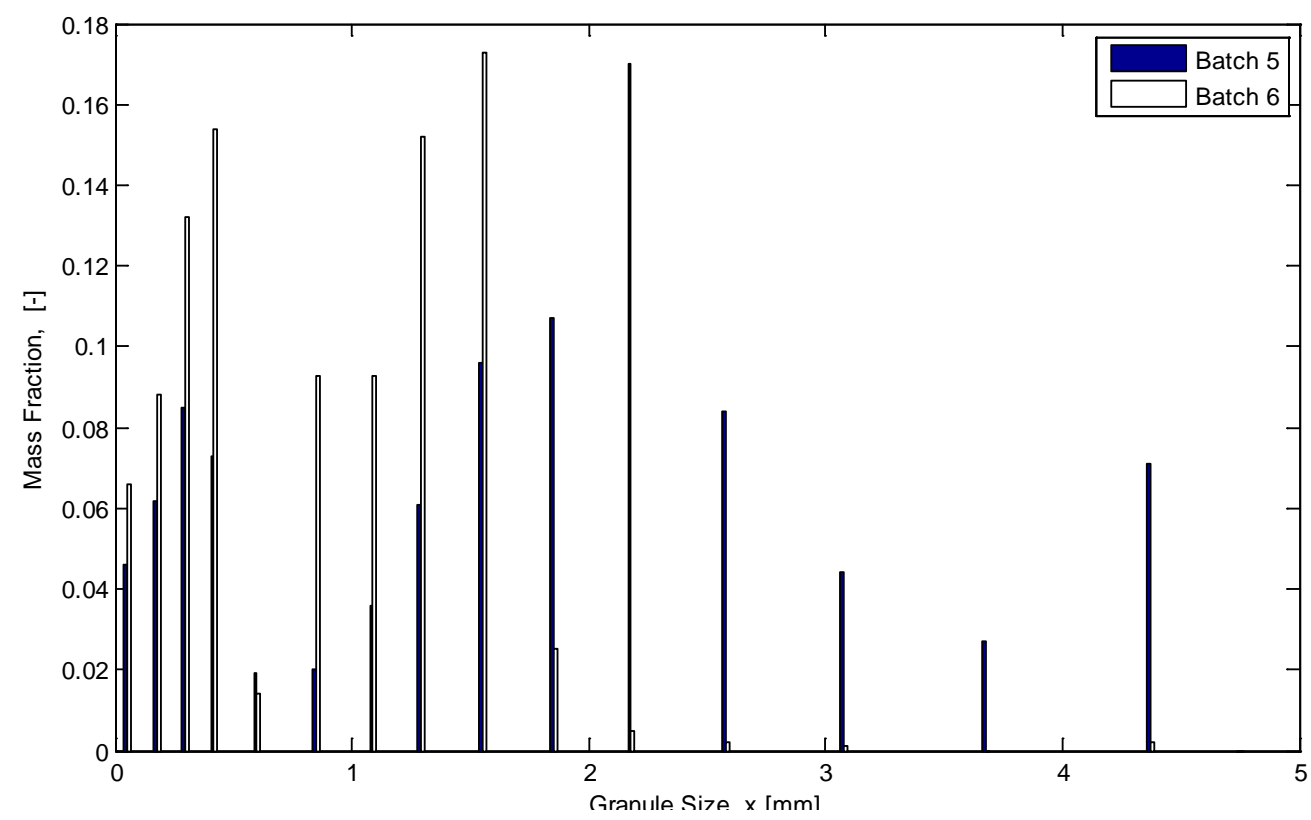

616 Fig. 4: Comparison of granule size distributions of two different batches

617 


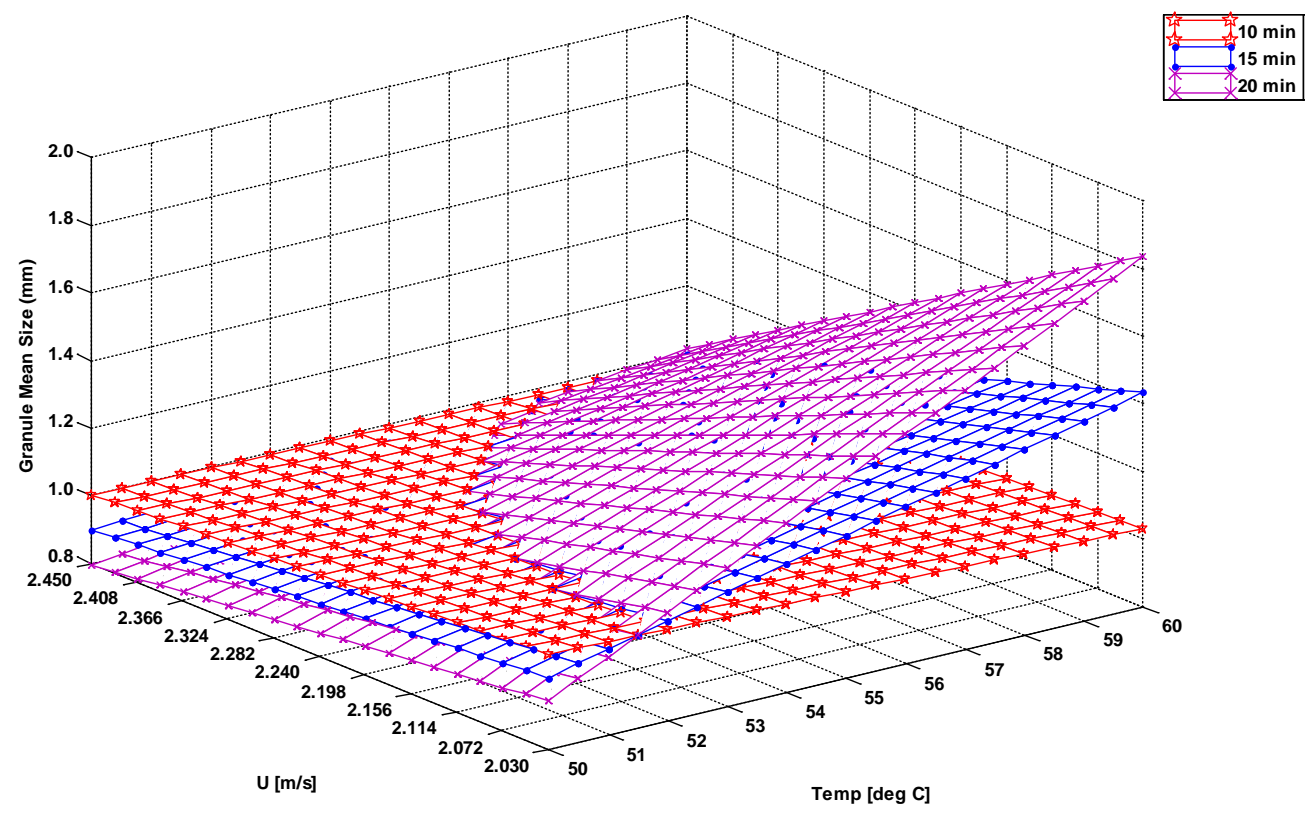

620

621 Fig. 5: Surface plot showing effect of fluidising air velocity and fluidised bed temperature on the granule 622 mass mean size for different granulation times.

623

624 


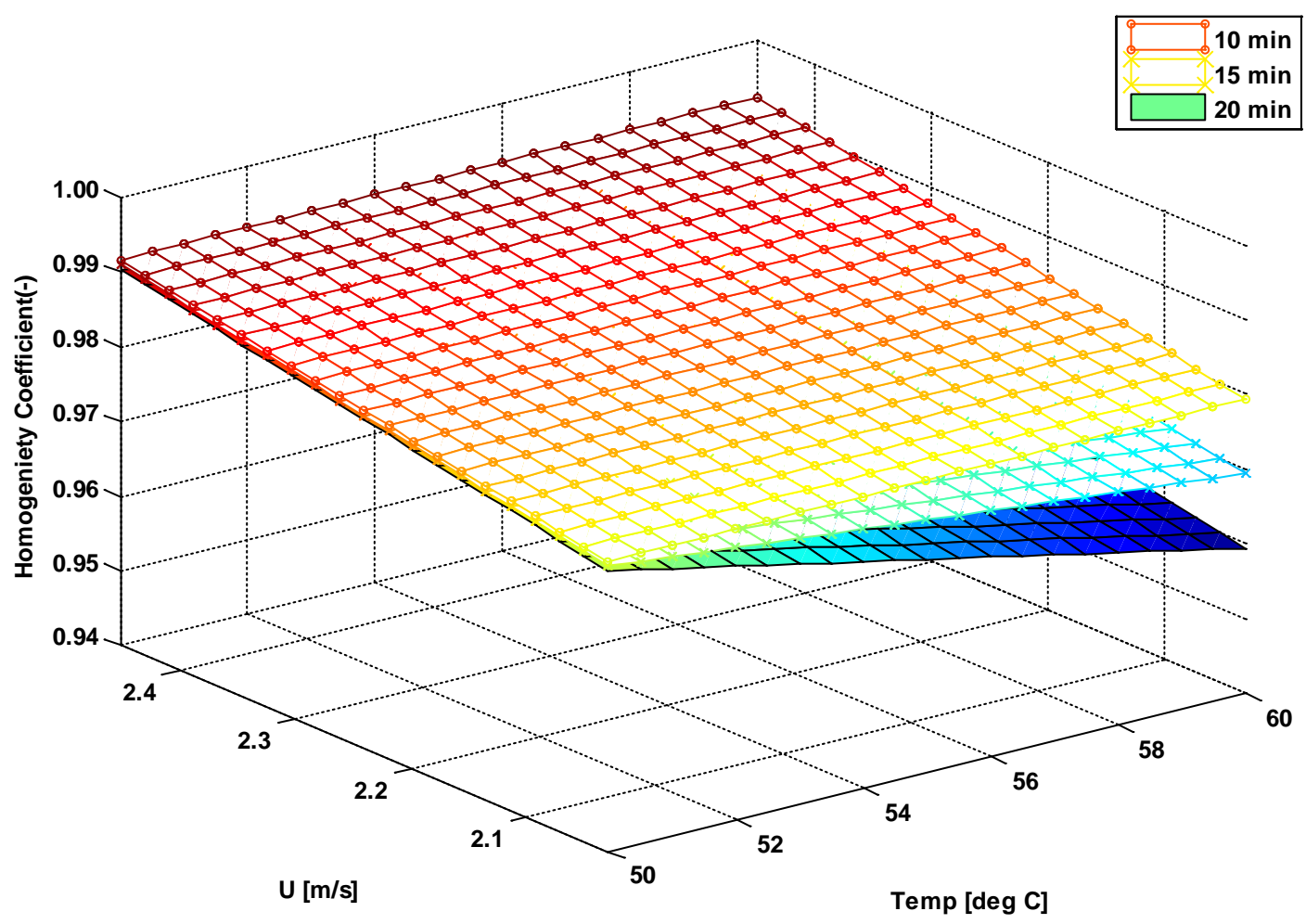

625

626 Fig. 6: Effect of fluidising velocity and bed temperature on the granule homogeneity for three different 627 processing times.

628 


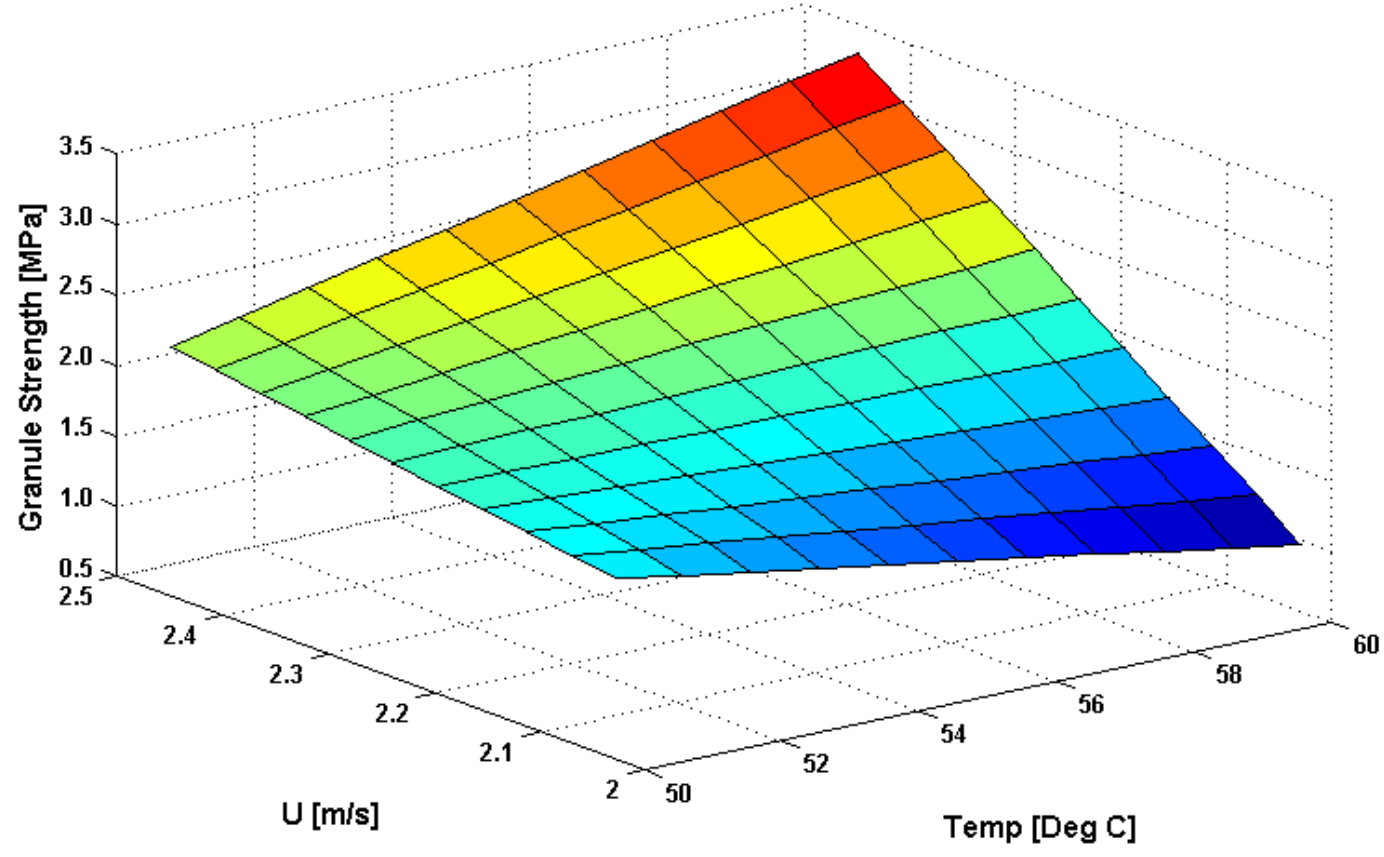

630 Fig. 7: effect of process variables on the granule strength. Granules used in the test were in the size range $631 \quad 1.4$ to $1.7 \mathrm{~mm}$.

632 


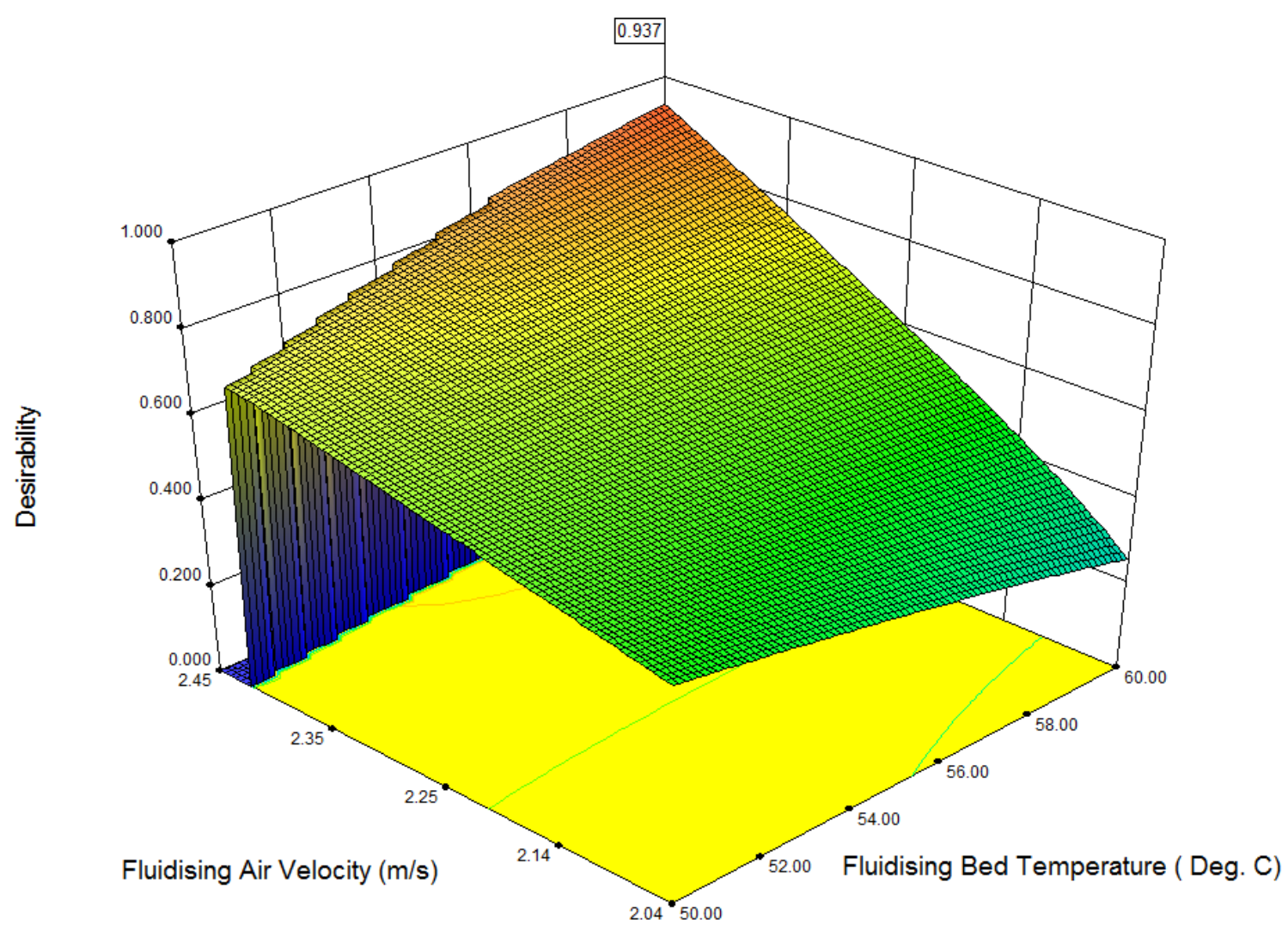

633

Fig. 8: Desirability plot.

636

637

638 